\title{
FRACTOGRAFIA DE JUNTAS SOLDADAS PELOS PROCESSOS GTAW, SMAW E FCAW DE ACCO INOX DUPLEX 2205 APÓS ENSAIO DE TRAÇÃO *
}

\author{
Willy Ank de Morais ${ }^{1}$ \\ Diego Salgado Prado ${ }^{2}$ \\ Douglas Oliveira de Souza ${ }^{3}$ \\ Fabio Ferreira de Souza ${ }^{4}$ \\ Nilton Ferreira da Silva Neto ${ }^{5}$
}

\section{Resumo}

Este trabalho teve como objetivo analisar, através da fractografia, o desempenho de aços inoxidáveis Duplex 2205 soldados por três processos diferentes: FCAW - FluxCored Arc Welding (Arame Tubular), o GTAW - Gas Tungsten Arc Welding (TIG), e o SMAW - Shielded Metal Arc Welding (Eletrodo Revestido). A superfície de fratura das amostras foi obtida através de ensaios de tração, nos quais foram registradas as respectivas curvas tensão-deformação completas, que também foram analisadas. Os resultados mostraram que o tipo de influência da solda nas propriedades mecânicas analisadas.

Palavras-chave: Fractografia; Mecânica da Fratura; Aço Inox Duplex 2205.

\section{FRACTOGRAPHY OF STAINLESS STEEL DUPLEX 2205 WELDED JOINTS OBTAINED BY GTAW, SMAW AND FCAW PROCESSES AFTER TENSILE TEST}

\begin{abstract}
This study aimed to analyze, through fractography, the performance of Duplex Stainless Steel 2205 welded by three different processes - Flux-Cored Arc Welding (tubular wire), the Gas Tungsten Arc Welding (GTAW), and Shielded Metal Arc Welding (SMAW). The fracture surface of the specimens was obtained by tensile test, with the recording of the complete stress-strain curves, that were analyzed too. The results showed that the type of weld influence on the mechanical properties analyzed.
\end{abstract}

Keywords: Fractography; Fracture Mechanics; Stainless Duplex Steel 2205.

1 Doutorando, Mestre, Engenheiro e Técnico em Metalurgia e Materiais, Sócio-Diretor da Willy Ank Soluções Metal-Mecânicas, Professor Mestre da UNAERP-Guarujá e Professor Adjunto da Universidade Santa Cecília (UNISANTA), Santos, SP, Brasil (willyank@unisanta.br).

2 Engenheiro mecânico UNISANTA, técnico em eletrônica, mecânico de usinagem, Santos, SP, Brasil (diegosalgado93@hotmail.com).

3 Pós-Graduando em Engenharia de Segurança do Trabalho - UNISANTA. Engenheiro Mecânico UNISANTA. Técnico em Metalurgia - ETEC Dona Escolástica Rosa. Técnico Laboratório Industrial - USIMINAS Cubatão, SP, Brasil (souza.douglas.oliveira@gmail.com).

4 Engenheiro Mecânico - UNISANTA. Técnico em Logística - ETEC Cubatão. Técnico em Medição e Controle / Planejamento - Consórcio Tomé-Technip, Cubatão, SP, Brasil (ff.souuza@gmail.com).

5 Engenheiro Mecânico, UNISANTA, Santos, SP, Brasil (nilton.neto@consorcioctt.com.br). 


\section{INTRODUÇÃO}

A Mecânica da Fratura permite o estudo do comportamento dos materiais quando submetidos à presença de descontinuidades internas ou superficiais, trincas e concentrações de tensões. A fractografia é uma importante técnica para a análise de fraturas e de documentação dos mecanismos que levaram a falha [1]. Essa técnica consiste em identificar aspectos morfológicos da topologia de uma superfície fraturada e, desta forma, estabelecer as relações com a sequência de eventos que levaram a fratura e possibilitar o entendimento do comportamento dos materiais [2]. Uma das maneiras mais simples de prever o comportamento mecânico dos materiais é através do ensaio de tração [3], a partir do qual é possível obter informações valiosas sobre características das fraturas em vários materiais.

Um material que vem sendo largamente utilizado na indústria química [4], petroquímica e de papel e celulose é o Aço Inoxidável Duplex, que combina elevada resistência mecânica e à corrosão [5]. Os aços inoxidáveis dúplex podem ser definidos como uma família de aços contendo duas fases, formando uma microestrutura ferrítica-austenítica - que dá origem ao termo "Duplex" [6].

O aço inoxidável 2205 é considerado um aço de alta liga e se caracteriza por apresentar resistência à corrosão intermediaria, sendo que, entre os duplex, este é o tipo mais empregado [6]. Segundo Padilha et. al. [7] a combinação entre os elevados valores de alongamento da austenita com o elevado limite de escoamento da ferrita, presentes no aço inoxidável duplex, formam um conjunto de propriedades mecânicas excelentes para diversas aplicações.

Neste sentido, este trabalho tem como objetivo analisar fractograficamente as superfícies de ruptura obtidas por meio de ensaio de tração em corpos de prova de Aço Inoxidável Duplex 2205, que foram soldados por três processos diferentes e tradicionais de solda deste material: TIG (GTAW), Arame Tubular (FCAW) e Eletrodo Revestido (SMAW).

\section{MATERIAIS E MÉTODOS}

Os corpos de prova (CPs) foram fabricados a partir de chapas soldadas de aço Inoxidável duplex 2205, cuja composição química nominal apresenta $0,04 \% \mathrm{C}$, $22 \% \mathrm{Cr}$ e $5 \% \mathrm{Ni}$. Os limites de resistência ( $S_{L R}$ ) e de escoamento ( $S_{L E}$ ) esperados para o material usado no ensaio são de $655 \mathrm{MPa}$ e $400 \mathrm{MPa}$ respectivamente. As amostras de material foram cortadas nas dimensões mostradas no Tabela 1 e soldadas pelos processos TIG, de Eletrodo Tubular e de Eletrodo Revestido [5]. A Figura 1 mostra os CPs antes do ensaio, soldados por meio dos três processos diferentes.

Tabela 1. Dimensões dos CPs empregados neste estudo.

\begin{tabular}{|c|c|c|c|c|c|c|c|c|c|c|}
\hline \multicolumn{11}{|c|}{ Medidas em $\mathrm{mm}$} \\
\hline & & \multicolumn{3}{|c|}{$\begin{array}{c}\text { FCAW } \\
\text { (Arame Tubular) }\end{array}$} & \multicolumn{3}{|c|}{$\begin{array}{c}\text { TIG } \\
\text { (Tungstein Inert Gas) }\end{array}$} & \multicolumn{3}{|c|}{$\begin{array}{c}\text { SMAW } \\
\text { (Eletrodo Revestido) }\end{array}$} \\
\hline & & CP3 & CP2 & CP3 & CP1 & CP2 & CP3 & CP1 & CP2 & CP3 \\
\hline \multirow{2}{*}{ Externo 1} & $t$ (espessura) & 5,15 & 5,07 & 4,45 & 4,42 & 5,07 & 4,90 & 5,10 & 4,35 & 5,18 \\
\hline & W (largura) & 8,04 & 8,02 & 7,81 & 8,03 & 8,01 & 8,03 & 7,69 & 7,92 & 8,03 \\
\hline \multirow{2}{*}{ Solda } & t (espessura) & 4,75 & 5,00 & 4,53 & 4,69 & 5,12 & 4,86 & 4,90 & 4,31 & 5,23 \\
\hline & W (largura) & 7,08 & 6,95 & 7,25 & 7,92 & 7,69 & 8,29 & 7,15 & 7,12 & 7,24 \\
\hline \multirow{2}{*}{ Externo 2} & $t$ (espessura) & 4,39 & 5,18 & 4,52 & 4,72 & 4,79 & 4,80 & 4,80 & 4,26 & 5,13 \\
\hline & W (largura) & 7,72 & 7,82 & 7,99 & 8,03 & 8,00 & 8,04 & 8,03 & 8,01 & 7,62 \\
\hline
\end{tabular}


Os CPs foram submetidos a ensaio de tração em máquina Emic com capacidade de $100 \mathrm{kN}$. Em seguida a superfície de fratura foi analisada através de um estéreo microscópio em ampliações de 10 a 40X. A Figura 2 ilustra a realização dos ensaios de tração, nos quais empregou-se extensômetria.

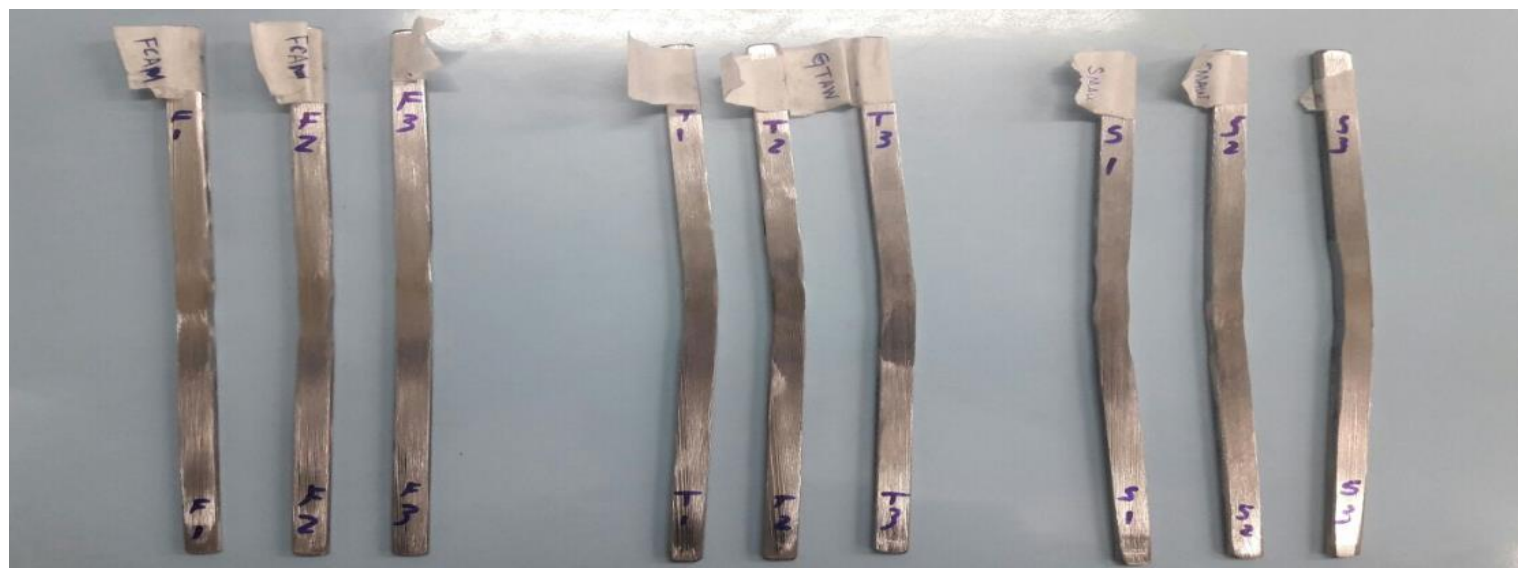

Figura 1. Amostras obtidas a partir de chapas soldadas.
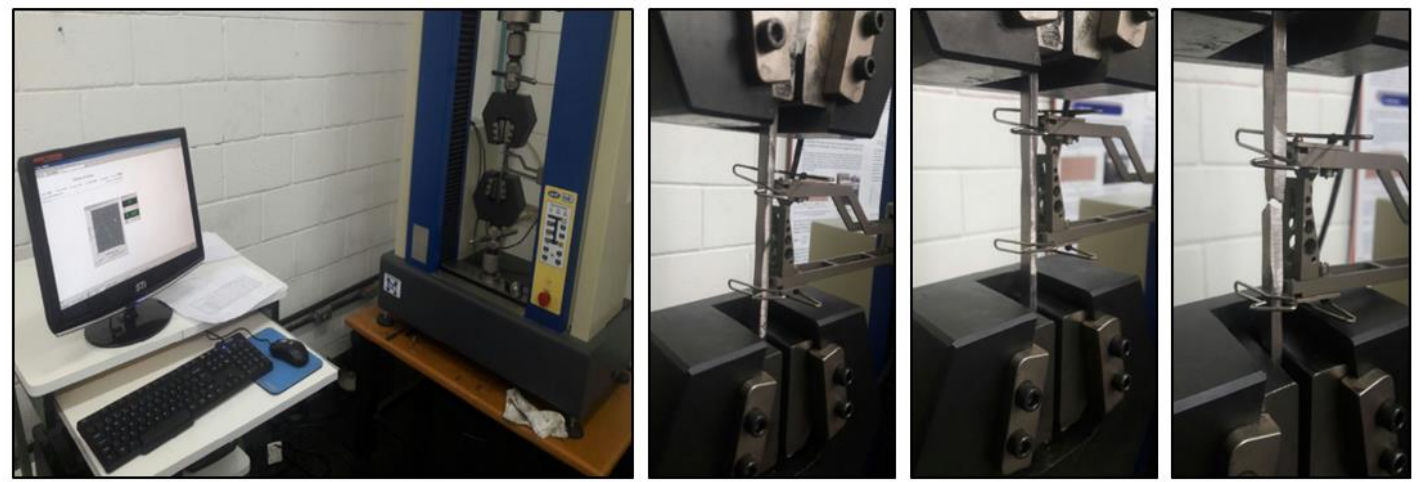

Figura 2. Equipamento de tração e corpos de prova sendo testados com uso de extensiometria.

\section{RESULTADOS E DISCUSSÃO}

$\mathrm{Na}$ Tabela 2 estão indicados os resultados da dureza média obtidas nas regiões do metal base (MB), Zona Termicamente Afetada pelo calor (ZTA) e metal de adição ou de solda (MS). Pelos valores encontrados não houve uma diferença significativa desta propriedade entre os três processos de soldagem.

Tabela 2. Durezas HRb obtidas nos corpos de prova soldados pelos três processos.

\begin{tabular}{clccc}
\hline Região & & FCAW & TIG & SMAW \\
\hline Metal Base & (MB) & 97 & 98,3 & 99 \\
Zona Termicamente Afetada & (ZTA) & 100 & 101 & 100 \\
Metal de Adição ou de Solda & (MS) & 97,7 & 84 & 86 \\
\hline
\end{tabular}

\subsection{Análise dos CPs soldados pelo processo de arame tubular (FCAM)}

A Figura 3 apresenta os diagramas tensão versus deformação de engenharia obtidos durante os ensaios com as amostras obtidas pela soldagem do aço inoxidável duplex 2205 pelo processo FCAW. 

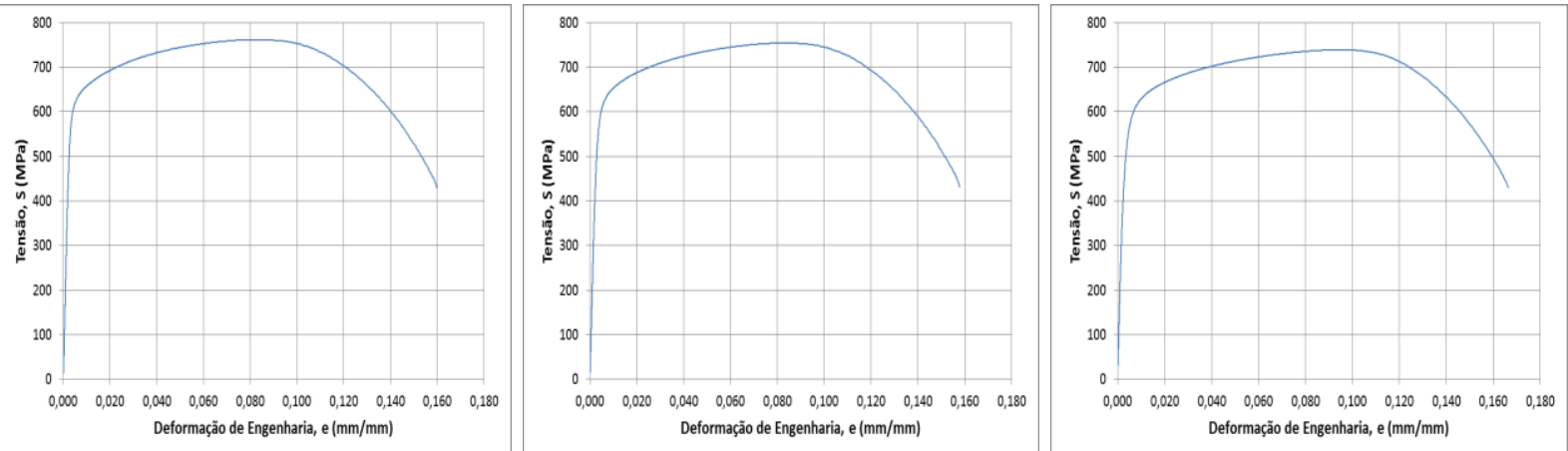

Figura 3. Diagramas tensão versus deformação de engenharia para os três CPs soldados pelo processo FCAW.

Ao se analisar a superfície de fratura pode-se observar uma fratura do tipo "taçacone", característica de materiais dúcteis. Esta característica pode ser confirmada ao se analisar o diagrama de tensão $x$ deformação, pois o mesmo apresenta elevada deformação antes da fratura. A superfície de fratura apresenta a presença de uma zona cisalhante e de uma zona fibrosa observada através de microscópio estereoscópico. Este comportamento foi observado em todos os $3 \mathrm{CPs}$ oriundos de amostras soldadas pelo processo FCAW. A Figura 4 ilustra a superfície de fratura descrita.

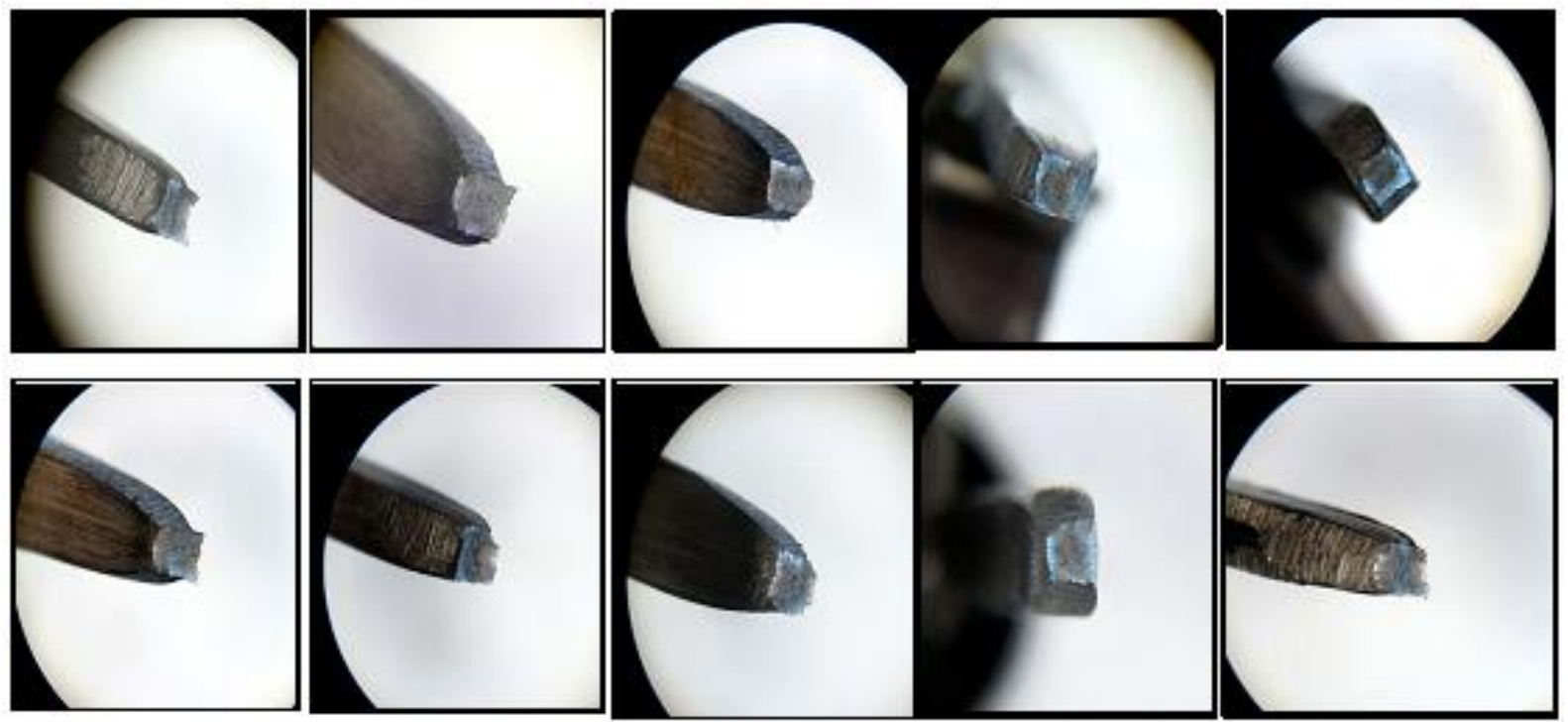

Figura 4. Superfície de fratura dos CPs com solda FCAW.

\subsection{Análise dos CPs soldados pelo processo TIG (GTAM)}

Durante a análise das superfícies de fratura e dos diagramas de tensão versus deformação das amostras soldadas pelo processo TIG foi possível observar a presença de deformação plástica, que caracteriza fratura dúctil, porém em um nível de deformação menor do que a observada nos corpos de prova FCAW (Figura 3). A Figura 5 apresenta os diagramas tensão versus deformação de engenharia obtidos durante os ensaios com as amostras obtidas pela soldagem do aço inoxidável duplex 2205 pelo processo GTAW.

A Figura 6 ilustra as superfícies de fratura resultantes do ensaio, nas quais podem ser observadas algumas regiões de clivagem. Nestas regiões ocorreram destacamento súbito sem deformação, o que deveria caracterizar um 
comportamento parcialmente frágil dos corpos de prova. Porém ao se observar os gráficos da Figura 5, conclui-se que esta superfície de fratura se formou após o início da estricção, pois as curvas não apresentam uma queda abrupta da carga ao longo do processo de deformação plástica dos CPs. É certo que o nível de plasticidade foi diminuído, ao se comparar o nível total de alongamento registrado nestas amostras soldas pelo processo GTAW em relação às amostras soldadas pelo processo FCAW.
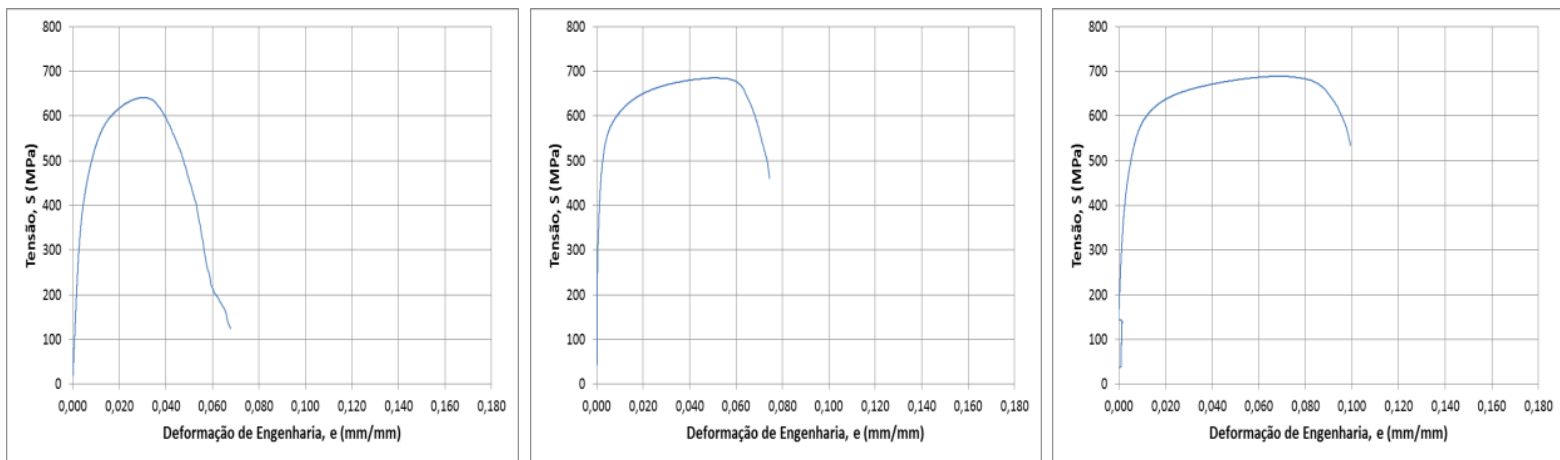

Figura 5. Diagramas tensão versus deformação de engenharia para os três CPs soldados pelo processo GTAW.

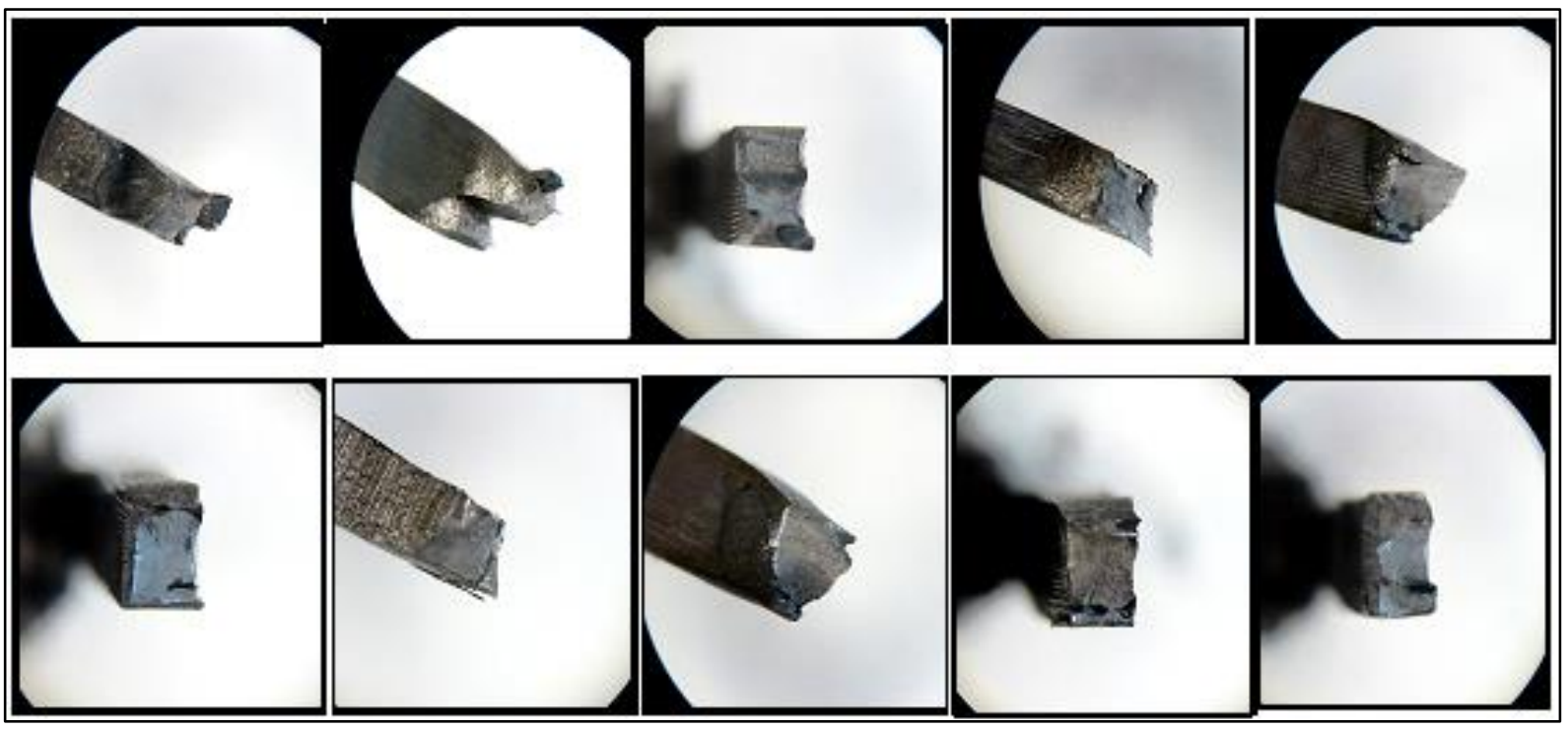

Figura 6. Superfície de fratura dos CPs com solda GTAW.

\subsection{Análise dos CPs soldados pelo processo de eletrodo revestido (SMAM)}

Foi possível observar nos CPs soldados pelo processo SMAW uma fratura com um comportamento similar na superfície de fratura e nos diagramas tensão versus deformação, quando comparados aos CPs soldados pelo processo GTAW. Analisando-se os gráficos com os resultados finais, nota-se que o alongamento dos CPs SMAW foi maior que nos CPs GTAW e menor que nos CPs FCAW. A Figura 7 apresenta os diagramas tensão versus deformação de engenharia obtidos no ensaio com os corpos de prova soldados pelo processo SMAW.

A Figura 8 apresenta as superfícies de fratura para os três CPs soldados com eletrodo revestido (SMAW). Durante os ensaios realizados foi possível perceber uma considerável deformação plástica nos CPs, plasticidade esta que segundo Borsato [8] é causada pela presença de uma estrutura refinada obtida durante a 
transformação de parte da fase ferrítica para a combinação de estrutura austenítica/ferrítica. Ainda de acordo com Borsato [8], diversos autores afirmam que existe a possibilidade de soldagem deste aço sem prejuízo de suas propriedades mecânicas e de resistência à corrosão. Durante os ensaios não foi possível observar alterações nas propriedades esperadas em função das soldas aplicadas nos CPs.
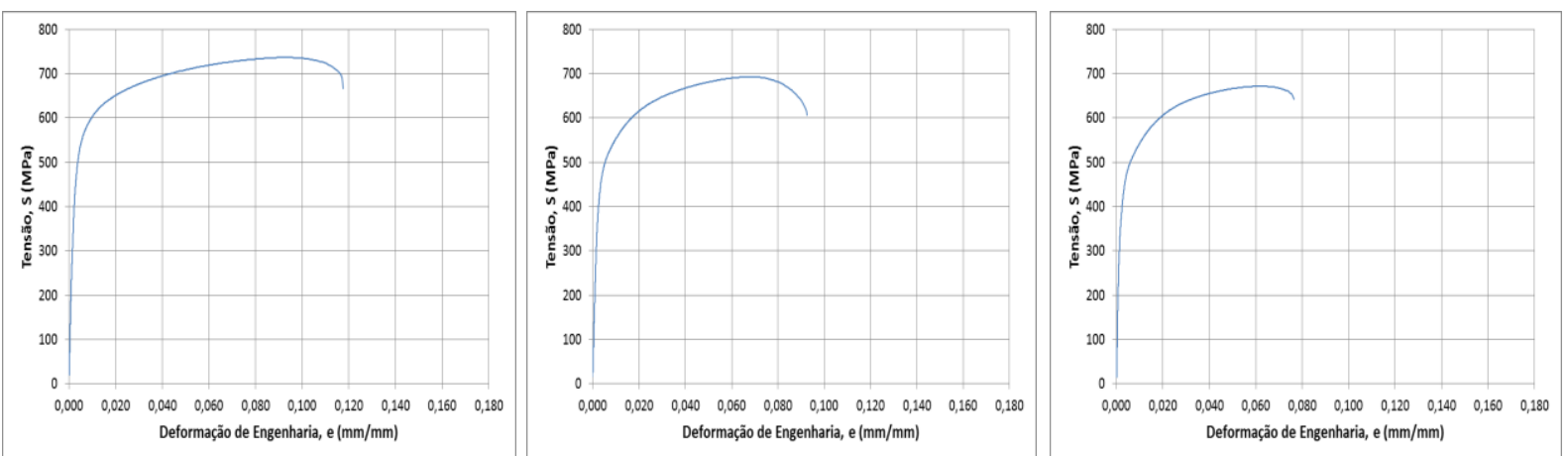

Figura 7. Diagramas tensão versus deformação de engenharia para os três CPs soldados pelo processo SMAW.

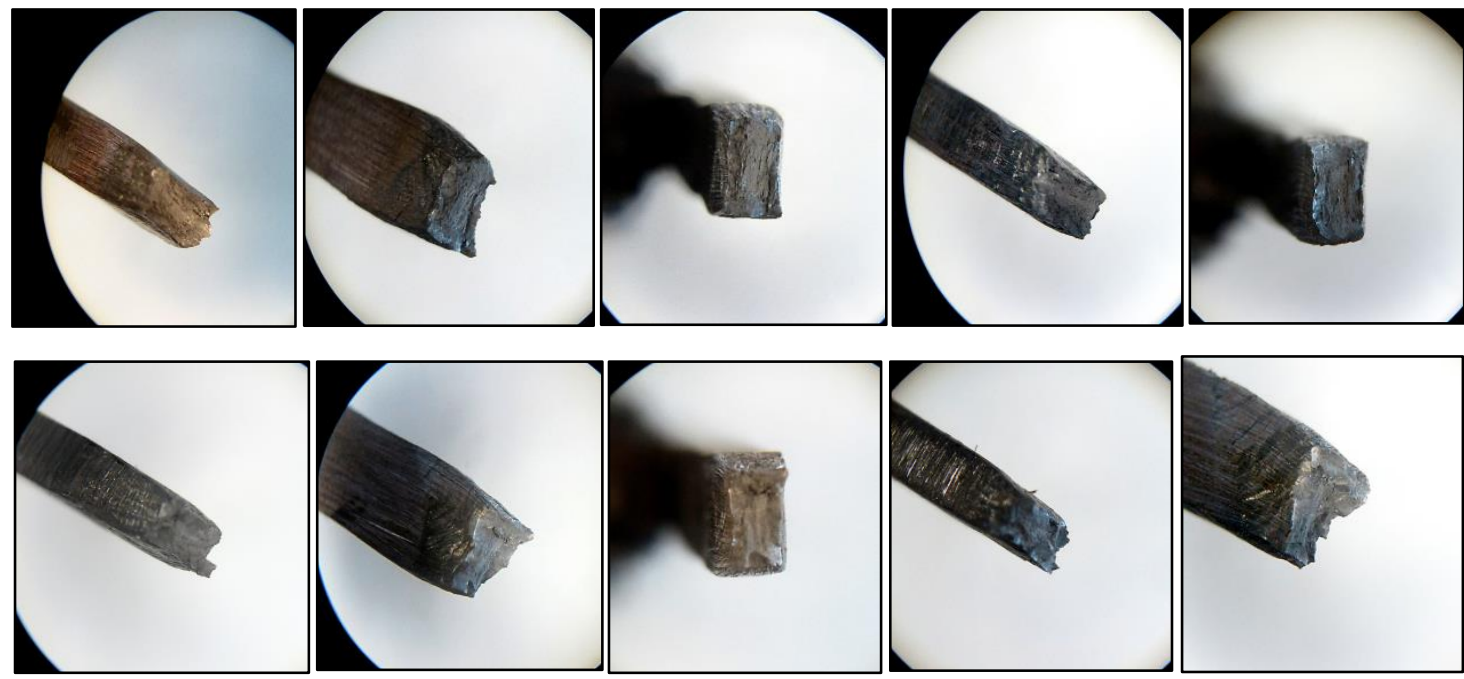

Figura 8. Superfície de fratura dos CPs com solda SMAW.

Os resultados obtidos dos ensaios de tração com os três processos estão sumarizados na Tabela 3. Os dados apresentados atestam uma melhor combinação entre a resistência mecânica da soldagem com arame tubular, assim como o alongamento obtido no teste desta junta soldada. Considerando que a tenacidade de um material depende da combinação entre resistência mecânica e de sua ductilidade (alongamento) [9], então a junta soldada pelo processo FCAW também deve apresentar a melhor tenacidade. O processo TIG apresentou um pior desempenho, apesar de que os resultados de resistência são aceitáveis para a junta. Este comportamento podes ser atribuído ao caráter mais manual da execução da junta soldada TIG, que demanda maior habilidade manual do soldador.

Tabela 3. Resultados dos ensaios de tração das juntas soldadas.

\begin{tabular}{ccccc}
\hline Processo & Ruptura & SLE (MPa) & SLR (MPa) & \%Along. \\
\hline FCAW & Metal Base & $570 \pm 28$ & $755 \pm 13$ & $16 \pm 0,5$ \\
TIG & Metal de Solda & $470 \pm 25$ & $672 \pm 28$ & $8 \pm 1,9$ \\
\hline
\end{tabular}




\section{CONCLUSÃO}

A fractografia é um importante método de avaliação das causas da fratura que também pode ser empregada como uma ferramenta para a análise do desempenho estrutural de materiais ou, no caso deste trabalho, de uma junta soldada. Neste trabalho foi possível observar que os processos de soldagem por arame tubular (FCAW) e TIG (GTAW) e por eletrodo revestido (SMAW) tem pouca influência nas propriedades mecânicas da junta do aço inoxidável 2205.

A análise da superfície de fratura e dos diagramas de tensão versus deformação de engenharia mostrou que ocorre um processo de fratura plástica (dúctil) com razoável deformação nos corpos de prova, especialmente para a experiência feita com o arame tubular. No caso em particular da soldagem TIG efetuada, a capacidade de deformação plástica observada foi menor o que reflete o aspecto fratográfico obtido nos corpos de prova, os quais apresentaram delaminações das camadas de solda depositadas.

\section{Agradecimentos}

Os autores gostariam de agradecer à doação do consumível de soldagem FCAW pela empresa voestalpine Böhler Welding Soldas do Brasil Ltda, obtido pela atuação do Sr. Aparecido Benedito Garcia. Os autores também agradecem à empresa INSPE///BRAS no fornecimento dos consumíveis de solda TIG e SMAW, dos equipamentos de soldagem e da mão de obra para a execução das juntas soldadas analisadas neste trabalho.

\section{REFERÊNCIAS}

1 MORAIS, W A. A Análise de Falhas: Parte 2 Morfologias Básicas da Superfície da Fratura. Metal Mecânica. 2014 Junho; 1-103;

2 CÂNDIDO, G. M. Fractografia de Compósito Estrutural Aeronáutico Submetido à Caracterização de Tenacidade à Fratura Interlaminar em Modo I. Polímeros. 2012 março;

3 GREENHALGH, E.S. Failure Analysis and Fractography of Polymer Composites. Woodhead Publishing Limited. 2009.

4 SENATORE, M.L.F.E.P. Estudo comparativo entre os aços inoxidáveis dúplex e os inoxidáveis AISI 304L/316L. REM: R. Esc. Minas, Ouro Preto. 2007 janeiro.

5 MAGNABOSCO, R. Projetos de Iniciação Científica. FEI (Faculdade de Engenharia Industrial). Disponível em: http://www.fei.edu.br/mecanica/me541/LabMat.htm. $<$ Acessado em 01/04/2016>.

6 FARIAS, F.A. Processamento do Aço Inoxidável Duplex por Extrusão em Canal Angular. 2009. Dissertação de mestrado.

7 PADILHA AF, PLAUT RL, RIOS PR. Stainless steels heat treatment. 2nd ed. Totten GE, editor. Boca Raton, FL, USA; 2007.

8 BORSATO K.S. Avaliação das propriedades mecânicas, microestrutura e cinética de precipitação de fase sigma do aço inoxidável dúplex UNS S31803. In Congresso Brasileiro de Engenharia e Ciência dos Materiais; Foz do Iguaçu. 2006.

9 MORAIS, W. A.; DIOGO, C. P. Características definidoras das aplicações dos aços planos - Parte 1: características físicas e propriedades mecânicas. Revista do Aço, São Paulo, v. 12, p. 18 - 23. 2014. 